\title{
ECOTERRORISMO E A RESPONSABILIDADE PENAL DAS EMPRESAS POR DANOS ECOLÓGICOS
}

\section{ECOTERRORISM AND THE PENAL RESPONSIBILITY OF COMPANIES FOR ECOLOGICAL DAMAGE}

${ }^{1}$ Jardel de Freitas Soares

\section{Resumo}

Os modelos legais não incriminadores existentes em nosso ordenamento jurídico não possuem a eficácia esperada, por isso, que a utilização de novos paradigmas criminológicos se mostra uma importante ferramenta na luta contra o ecoterrorismo. A metodologia a ser utilizada nesta pesquisa é o método hermenêutico-sistêmico exploratório. Deste modo, busca-se demonstrar que a imputação criminal das empresas pode ser realizada desde que se proceda a uma quebra de conceitos clássicos considerados intocáveis e uma harmonização do Direito com outras Ciências afins, dando origem, assim, a um sistema jurídico interdisciplinar e mais eficiente na proteção ambiental.

PALAVRAS-CHAVE: Criminológicos;Ecoterrorismo; Empresas;Interdisciplinar; Ambiental

\begin{abstract}
The non-incriminating legal models in our legal system do not have the expected effectiveness, therefore, that the use of new criminological paradigms is an important tool in the fight against ecoterrorism. The methodology to be used in this research is the exploratory hermeneuticsystemic method. In this way, it is tried to demonstrate that the criminal imputation of the companies can be carried out as long as a classic concepts considered untouchable and a harmonization of the Law with other related sciences are broken, thus giving rise to an interdisciplinary legal system and more efficient in environmental protection.
\end{abstract}

KEY WORDS: Criminological; Ecoterrorism; Companies; Interdisciplinary; Environmental

\footnotetext{
${ }^{1}$ Doutor e professor em Recursos Naturais pela Universidade Federal de Campina Grande, UFCG - Paraíba PB, (Brasil). Doutor em Ciências Jurídicas e Sociais pela Universidad del Museo Social Argentino - UMSA, (Argentina);E-mail: jardel.soares@uol.com.br
} 


\section{1-INTRODUÇÃO}

O modelo contemporâneo da economia e da política é marcado por uma globalização composta por grandes grupos empresariais, que exploram os recursos naturais de maneira predatória e faz surgir o que se denomina de terrorismo ambiental ou ecoterrorismo. Nesta figura delitiva os bens atingidos são macrossociais cujos resultados danosos atingem a todos os seres vivos de maneira indistinta.

Justifica-se o estudo acadêmico na perspectiva de que as empresas possuem atualmente um alto grau de organização e autonomia semelhante a uma pessoa física, e, portanto, deve ser punida criminalmente por danos aos bens jurídicos tutelados, dentre estes os bens ecológicos, que sofrem com as atividades empresariais em nome de uma economia de mercado em que lucro pecuniário está em primeiro lugar, a exemplo do caso no município de Mariana, no Estado de Minas Gerais, bem como, o desastre nuclear de Chernobyl durante a guerra fria, na extinta URSS, onde as dimensões catastróficas são sentidas até os dias atuais.

O objetivo geral da pesquisa é analisar as teorias e as aplicações práticas da responsabilização das pessoas jurídicas face ao terrorismo ambiental contemporâneo com um olhar interdisciplinar.

Quanto aos objetivos específicos pretende-se: promover uma abordagem inovadora e uma crítica paralela acerca da responsabilidade penal das pessoas jurídicas no ordenamento jurídico brasileiro por danos ambientais transfronteiriço; provar que a responsabilização criminal da pessoa coletiva é plenamente compatível com a tradicional teoria do delito, da culpabilidade e das funções da pena, desde que se adote a tendência moderna de flexibilização da dogmática jurídico-penal e supere a visão única do Direito Criminal clássico que compreende a perspectiva estritamente antropocêntrica.

De acordo com tais argumentos, surge então a seguinte problemática: quais as possíveis relações jurídicas que existe entre a degradação ambiental transfronteiriça empresarial e o terrorismo ambiental?

A metodologia a ser utilizada nesta pesquisa consiste no método hermenêuticosistêmico exploratório, pois visa proporcionar uma maior familiaridade com o problema e torná-lo explícito, além de construir novas hipóteses a serem estudadas. O procedimento metodológico utiliza-se de uma ampla pesquisa nas doutrinas, no meio eletrônico oficial e fundamentalmente nas jurisprudências dos Tribunais Superiores brasileiros. E como não poderia deixar de se fazer em um trabalho acadêmico, efetua-se também uma rigorosa pesquisa 
de Direito Comparado com a finalidade de um maior aprofundamento da evolução histórica e a conceituação teórica da conversão dos sistemas jurídicos envolvidos.

Deste modo, observa-se que a proteção ao meio ambiente está ligada intrinsicamente ao direito à vida, não somente as dos seres humanos, mas de todo o planeta. E a Ciência Criminal não pode ficar inerte diante do avanço do terrorismo ambiental provocada pelas pessoas jurídicas, sobretudo após o fortalecimento do processo da globalização.

\title{
2- DO TERRORISMO AMBIENTAL E SEUS ASPECTOS
}

A terminologia terrorismo significa impor o terror movido por preceitos religiosos, políticos, ideológicos e equiparados em detrimento da paz ou segurança coletiva ${ }^{2}$. Indubitavelmente é uma das formas criminosas mais preocupantes da sociedade de hoje devido aos seus efeitos devastadores em inúmeros aspectos, cujos aparatos executórios se sofisticam a cada dia e se tornam de difícil controle preventivo por parte dos órgãos competentes.

Cunha (2009, p.37) explica a preocupação internacional com a atuação e operacionalização terrorista ao dizer:

\begin{abstract}
Muitos apontam para o alto poder destrutivo de que os atentados podem valer-se atualmente. Armas potentes estão, pela primeira vez, disponíveis aos terroristas, sendo de difícil rastreamento. Sua tecnologia é de fácil operação e seu custo não é impraticável. Na visão de W. Laqueur, isso significaria uma transformação radical, talvez uma revolução, na natureza do terrorismo.
\end{abstract}

Advogam Jakobs e Meliá (2007) que os agentes terroristas não devem ser tratados como cidadãos comuns, no qual os direitos e garantias constitucionais não podem prevalecer em seu julgamento. Os terroristas obrigatoriamente passam a ser tratados como inimigos da sociedade devido os altos riscos que promovem. Estão em constante guerra com as instituições, e por isso, não merecem ter os mesmos direitos garantidos ao cidadão comum. Cabe, portanto, ao Direito Penal do inimigo promover a segurança a qualquer custo frente aos criminosos que persistem em promover o terror.

Contrapondo-se a esta teoria, o jurista italiano Luigi Ferrajoli (2013), defende o Garantismo Penal como mecanismo legitimador das sanções penais a todos os indivíduos

\footnotetext{
${ }^{2}$ A nova Lei brasileira de $\mathrm{n}^{\mathrm{o}}$ 13.260/2016 conceitua da seguinte forma o crime de terrorismo: Art. $22^{\circ} \mathrm{O}$ terrorismo consiste na prática por um ou mais indivíduos dos atos previstos neste artigo, por razões de xenofobia, discriminação ou preconceito de raça, cor, etnia e religião, quando cometidos com a finalidade de provocar terror social ou generalizado, expondo a perigo pessoa, patrimônio, a paz pública ou a incolumidade pública.
} 
indistintamente no Estado Democrático de Direito. Desta forma, deve-se prevalecer o respeito ao princípio da dignidade da pessoa humana e aos Direitos Fundamentais sob pena da deslegitimação das instituições democráticas. Orienta-se que o Direito Penal interfira minimamente e quando atuar garanta que os agentes criminosos, mesmo que sejam terroristas, tenha um processo justo e humanizado.

No entanto, independente das correntes que se adotem, o terrorismo que se preocupa em debater nesta pesquisa nasce a partir da presente conjuntura político-econômica mundial, no qual prevalece o lucro como seu objetivo primordial em detrimento dos nossos recursos naturais. Surge então, a macrocriminalidade ambiental, também denominado ecoterrorismo ou terrorismo ambiental, um fenômeno criminológico em que a dimensão vitimológica atinge vários espaços físicos e um número elevado de seres vivos, e que interfere por tempo indeterminado na cadeia ecológica, ou seja, pode ser facilmente considerado tão ou muito mais devastador do que o terrorismo convencional.

É uma forma de criminalidade recente, causadas principalmente pelas pessoas jurídicas no exercício de suas atividades econômicas excessivamente organizadas, nas quais as atuais concepções de culpabilidade e de aplicações de penas não estão preparadas devidamente para coibir estas ameaças de grande terror. "El derecho Penal moderno antes de estas transformaciones sociales tienden a crear nuevos dogmas y experiencia, pues sólo así será capaz de seguir el ritmo de las nuevas realidades y ser más efectivo.” (SOARES, 2013, p.53)

Para Fattorelli (2015) o ecoterrorismo é um tipo de criminalidade que além de demonstrar o egoísmo dos grupos econômicos traduz uma dívida social e ecológica que perdura por gerações, quando relata que:

\footnotetext{
A vontade de obter lucros excessivos com a atividade de mineração no Brasil - de forma predatória, acelerada e descontrolada, arrancando da Terra o máximo de minerais possível, no menor tempo e ao menor custo - tem significado a imposição sistemática de terror à população e ao meio ambiente.

Os únicos beneficiários desse terrorismo têm sido os donos das grandes mineradoras nacionais e estrangeiras que atuam no Brasil. Além de obterem lucros bilionários com a venda do minério, utilizarem água à vontade e de graça, ainda usufruem de diversos benefícios tributários, como incentivos fiscais à exportação, isenção na distribuição de lucros e isenção para a remessa de tais lucros ao exterior.

As vítimas do terrorismo têm sido:

- toda a população atingida em seu direito à vida, à liberdade, à segurança e à propriedade, e

- a própria Natureza, que além de mutilada sem o menor respeito ainda recebe toneladas de rejeitos contaminados. A Dívida Ecológica que tem sido gerada por esses processos é incalculável.
} 
A Constituição Federal brasileira de 1988 preconiza em seu artigo $4^{\circ}$, VIII e $5^{\circ}$, XLIII, o seguinte no que se refere a temática do terrorismo:

Art. $4^{\circ}$ A República Federativa do Brasil rege-se nas suas relações internacionais pelos seguintes princípios:

$[\ldots]$

VIII - repúdio ao terrorismo e ao racismo;

Art. $5^{\circ}$ Todos são iguais perante a lei, sem distinção de qualquer natureza, garantindose aos brasileiros e aos estrangeiros residentes no País a inviolabilidade do direito à vida, à liberdade, à igualdade, à segurança e à propriedade, nos termos seguintes: $[\ldots]$

XLIII - a lei considerará crimes inafiançáveis e insuscetíveis de graça ou anistia a prática da tortura, o tráfico ilícito de entorpecentes e drogas afins, o terrorismo e os definidos como crimes hediondos, por eles respondendo os mandantes, os executores e os que, podendo evitá-los, se omitirem; (destaque nosso)

Recentemente foi promulgada lei de $n^{0} 13.260 / 2016$ que regulamenta as previsões constitucionais anteriormente mencionadas sobre o terrorismo, no seu artigo $2^{\circ}$ e parágrafos expressa o seguinte:

$\S 1$ 1 São atos de terrorismo:

I - usar ou ameaçar usar, transportar, guardar, portar ou trazer consigo explosivos, gases tóxicos, venenos, conteúdos biológicos, químicos, nucleares ou outros meios capazes de causar danos ou promover destruição em massa;

IV - sabotar o funcionamento ou apoderar-se, com violência, grave ameaça a pessoa ou servindo-se de mecanismos cibernéticos, do controle total ou parcial, ainda que de modo temporário, de meio de comunicação ou de transporte, de portos, aeroportos, estações ferroviárias ou rodoviárias, hospitais, casas de saúde, escolas, estádios esportivos, instalações públicas ou locais onde funcionem serviços públicos essenciais, instalações de geração ou transmissão de energia, instalações militares, instalações de exploração, refino e processamento de petróleo e gás e instituições bancárias e sua rede de atendimento;

$\mathrm{V}$ - atentar contra a vida ou a integridade física de pessoa:

Pena - reclusão, de doze a trinta anos, além das sanções correspondentes à ameaça ou à violência. (destaque nosso)

Não obstante, a Carta Magna nacional eleva a nível constitucional a proteção do meio ambiente quando afirma:

Art. 225. Todos têm direito ao meio ambiente ecologicamente equilibrado, bem de uso comum do povo e essencial à sadia qualidade de vida, impondo-se ao Poder Público e à coletividade o dever de defendê-lo e preservá-lo para as presentes e futuras gerações. (destaque nosso) 
Prado (2005, p.77) explica a importância da previsão constitucional e da necessidade das leis infraconstitucionais, inclusive legislações penais, estarem sempre em harmonia no que tange a preservação ecológica:

\footnotetext{
Ademais, frise-se, como norma de caráter teleológico impõe uma orientação a todo o ordenamento infraconstitucional.

De confirmado com o novo texto constitucional, ficam patenteados o reconhecimento do direito-dever ao meio ambiente ecologicamente harmonioso, a obrigação dos poderes públicos e da coletividade de defendê-lo e de preservá-lo e a previsão de sanções para as condutas ou atividades a ele lesivas. A preservação do meio ambiente passa a ser a base em que se assenta a política econômica e social (art. $225, \S 1^{\circ}, \mathrm{V}$, $\mathrm{CF})$. (destaque no original)
}

Ao se realizar a interpretação teleológico-sistemática das normas alhures na busca do seu sentido e razão de sua existência, conclui-se que o combate ao terrorismo é um dos deveres natos do Estado Democrático nacional, onde a vida da natureza como um todo é a objeto jurídico principal a ser protegido e não apenas o ser humano individualmente ou coletivamente. “A mudança atual está caracterizada por uma concepção menos antropocêntrica e mais geocêntrica, isto é, a aparição da natureza como sujeito.” (LORENZETTI, 2010, p.30)

Vale ressaltar que a lei de combate ao terrorismo, $\mathrm{n}^{\circ} 13.260 / 2016$, apesar de ser muito recente possui ainda um caráter extremamente antropocêntrico, ou seja, restrito as atividades humanas e que não houve uma inovação legislativa diante da nova criminalidade ecológica, que é tão ou mais gravosa do que o terrorismo tradicional. Quando a Constituição Federal resolveu tutelar o meio ambiente o intuito é a proteção de todas as vidas, humana ou não, e ao alargar o sentido da norma constitucional constata-se que a criminalidade massiva em face aos recursos naturais é também um atentado a harmonia e paz mundial, já que as consequências desastrosas são transfronteiriças e erga omnes. Ou seja, restringir as atividades terroristas a apenas questões ideológicas é um imenso equívoco diante dos riscos e prejuízos atuais, em especial das grandes empresas, causados ao ecossistema do nosso planeta.

Portanto, diante de tais perspectivas discutidas a Ciência Criminal deve urgentemente se moldar aos novos problemas contemporâneos para melhor coibir o avanço da nova criminalidade advinda dos grandes interesses econômicos empresariais, que consequentemente devasta o meio ambiente e vitimiza massivamente os valores fundamentais da nossa sociedade. 


\title{
3- AS NOVAS PERSPECTIVAS EM FACE DOS DELITOS ECOLÓGICOS
}

A grandeza dos danos da criminalidade ambiental é considerada irreversível e prejudicial, já que o meio ambiente é único, interligado e intransferível. As perspectivas de proteção penal em relação aos bens ecológicos devem mudar totalmente, pois passaram de microssocial para macrossocial, de local para transfronteiriço, de individual para coletivo, de antropocêntrico para biocêntrico. Afirma Milaré et al (2013, p.35-36) sobre a mutação da criminalidade nos dias atuais e a iminente necessidade do Direito Penal acompanhar estas mudanças sociais, mutatis mutandis:

\begin{abstract}
A criminalidade, a longo do tempo, assumiu diferentes formas e modalidades, que não mais se restringem aos clássicos delitos constantes do Código Penal: homicídio, furto, roubo, aborto. Urge que o Direito Penal passe por uma adaptação de seus conceitos e princípios para proporcionar adequada prevenção e repressão aos crimes. Isso não significa que as conquistas do Direito Penal liberal devam ser abandonadas. Devem ser elas mantidas, com as necessárias modificações, para enfrentar a criminalidade que padece mutações contínuas.
\end{abstract}

Alguns inovadores paradigmas criminológicos surgem, até então muito questionados entre os estudiosos no Brasil, como forma de auxiliar no combate a esta nova modalidade de delito, destacam-se;

Em primeiro lugar à responsabilidade penal das pessoas jurídicas, cuja fundamentação encontra-se na constituição Federal de 1988 onde reza em seu artigo 225, §3 responsabilidade da conduta e atividades consideradas lesivas ao meio ambiente, em que seus infratores pessoas físicas ou jurídicas estarão sujeitas a sanções penais, administrativas e civis. Corroborando com esta premissa o artigo $173, \S 5^{\circ}$ do mesmo texto legal estabelece que as pessoas jurídicas, independente da responsabilidade individual dos dirigentes, serão responsáveis por atos praticados contra a ordem econômica, financeira e contra a economia popular. E posteriormente surge a lei de crimes ambientais de $n^{\circ} 9.605 / 98$, no qual a dispõe em seu artigo $3^{\circ}$ e seguintes sobre a responsabilidade penal e as penalidades dos entes coletivos por danos ao meio ambiente.

Enfatiza Marcão (2013, p.23-24) a importância das previsões legais pátrias sobre a reponsabilidade criminal e as sanções dos entes coletivos por crimes contra os recursos naturais:

Decorre inequívoca, do sistema normativo vigente, portanto, a possibilidade de responsabilidade penal da pessoa jurídica em se tratando de crime ambiental, e bem por isso a Lei n. 9.605/98 tratou de dispor a respeito das penas aplicáveis às pessoas 
jurídicas (art.21); das penas restritivas de direitos aplicáveis às pessoas jurídicas (art.22); da pena de prestação de serviços à comunidade pela pessoa jurídica (art.23); da desconsideração da pessoa jurídica (art. $\left.4^{\circ}\right)$ e da liquidação forçada da pessoa jurídica (art.24).

Mesmo com todas estas previsões legais a temática sucinta ainda muita controvérsia entre os juristas, de um lado os que defendem a imputação penal das corporações (societas deliquere potest). Segundo Roxin (2008) as sanções as empresas e aos agentes individuais terão um papel no futuro muito importante no combate à criminalidade econômica e ambiental.

Sob outra perspectiva os que entendem que tal disposição é impossível e inócua perante os dogmas jurídicos e a viabilidade empírica (societas deliquere non potest). Defende Zaffaroni (2010) que a responsabilidade penal da pessoa jurídica é ato inconstitucional, pois a lei processual, mais especificamente a brasileira, fora criada para sancionar as pessoas naturais e qualquer pretensão de punição dos entes coletivos fere o princípio do devido processo legal, e consequentemente a Constituição Federal. Então, enquanto as normas processuais não se adaptarem a esta nova forma de imputação criminal, não será possível incriminar as pessoas jurídicas.

Apesar das divergências a corrente da imputação penal dos entes coletivos vêm crescendo em vários ordenamentos jurídicos dos países pelo mundo inteiro, assim é o caso da Inglaterra, da Austrália, da França, dos Estados Unidos, do Brasil, do Chile, da Venezuela ${ }^{3}$, dentre outras nações que incorporaram ou adaptaram a teoria societas deliquere potest as suas demandas nas áreas econômico-financeiras e ou ambientais. Inclusive, algumas nações, embora não adotem expressamente a responsabilidade penal das pessoas coletivas, abrem exceções em suas legislações, a exemplo da Alemanha ${ }^{4}$ e da Espanha ${ }^{5}$.

A nível comunitário a União Europeia instituiu o Tratado Constitutivo da Comunidade Europeia (TCCE) e nos seus artigos 85 e 86 fez a previsão da responsabilidade penal da pessoa jurídica por crimes ambientais, contudo, esta norma possui natureza apenas recomendativa aos países que o compõem.

\footnotetext{
${ }^{3}$ Inclusive a Venezuela foi o primeiro país da América do Sul a responsabilizar as pessoas jurídicas por crimes ecológicos com a promulgação da lei 4.358/92.

${ }^{4}$ Não se aceita a imputação penal das pessoas jurídicas por fundamento do texto constitucional, contudo, existe um reconhecimento no que concerne à matéria de infrações administrativas, por meio de um Direito Penal Administrativo.
5 Após a reforma penal de 1995 implementou à responsabilização das pessoas jurídicas duas medidas; as consecuencias accesorias e a investigação envolvendo o actuar en nombre de outro. Estes institutos vêm causando muitas polêmicas entre os juristas espanhóis por seu caráter sui generis.
} 
No Mercosul foi criado uma previsão de imputação criminal das empresas, no Protocolo de Defesa da Concorrência, em 1996, cuja finalidade é tornar mais livre e harmônica a circulação de riquezas e combater a concorrência desleal das empresas entre os países pactuantes do bloco mercosulino.

A responsabilidade penal das empresas possui fulcro na teoria orgânica, também conhecida como teoria da realidade, de acordo com esta forma de pensamento a pessoa jurídica obteve um processo de organização tão elevado que a torna um ente especial nas relações sociais, passível, portanto, de direitos e responsabilidades igualmente especiais. Deste modo, os atos e mentes da pessoa física significam igualmente os atos e mentes da pessoa jurídica quando representadas em sua finalidade institucional. A pessoa jurídica é considerada apenas como um instrumento, um meio de proteção, nos planos das pessoas naturais que a comandam. "A teoria da realidade objetiva, nesse sentido, concebe a pessoa jurídica como uma pessoa real, um organismo social realmente existente, com vontade própria e vida autônoma em relação aos seus dirigentes.” (ROCHA, 2003, p.35)

Se manifesta nesta linha de pensamento Gomes-Jara Díez (2010, p.97-98) ao relatar sobre a capacidade de organização das empresas:

\footnotetext{
Desde una perspectiva tradicional del delito puede afirmarse que la capacidad de acción se ve así sustituida por una capacidad de organización, de tal manera que, si bien resulta complicado afirmar que una empresa actúa por sí misma, dichas dificultades se reducen considerablemente cuando se sostiene que, llegado determinado nivel de complejidad interna, la empresa comienza a organizarse a sí misma, a autoorganizarse. (destaque no original)
}

A teoria organicista busca afirmar e demonstrar que as instituições não são apenas seres artificiais e abstratos criados pelo Estado por meio de um ato normativo, ao contrário, defende-se que as pessoas jurídicas são seres reais e a sua existência, mesmo que não signifique o reconhecimento exatamente igual à de uma pessoa física, possuem uma vontade e consciência peculiar, e que podem inclusive ser responsabilizadas segundo as normas da Ciência Criminal.

No entendimento de Jakobs (2010) os entes coletivos possuem uma culpabilidade especial com fulcro em sua própria constituição como pessoa heteroadministrada. Possui caráter genuíno e cujas punições não deveriam se quer serem chamadas de penas, mas sim de coações. 
Nas palavras de Bacigalupo (2010, p.352) a imputação penal das pessoas jurídicas possuem finalidades próprias muito importantes diante criminalidade contemporânea, quais sejam:

\begin{abstract}
Según la doctrina dominante la finalidad que se persigue la institución de una norma que contemple la responsabilidad penal de las personas jurídicas es, en primer lugar, impedir los beneficios o ventajas que pueda obtener una persona jurídica por la comisión de un delito llevado a cabo en su interés. En segundo lugar, la posibilidad de imponer una sanción a las personas jurídicas tiene por finalidad fomentar que los órganos directivos de las mismas impidan dentro del ámbito de la empresa la comisión de infracciones, la vulneración de deberes del empresario o que las empresas se enriquezcan por medio de la comisión de injustos.
\end{abstract}

O Superior Tribunal de Justiça (STJ) já decidiu que é possível a responsabilização penal da pessoa jurídica, no entanto, é imprescindível que a pessoa jurídica somente poderá ser imputada criminalmente se a pessoa física também for responsabilizada. Uma responsabilidade paralela e indissociável entre a pessoa física e a pessoa jurídica ${ }^{6}$.

Por outro rasgo, a ministra Rosa Weber do Supremo Tribunal Federal (STF), recentemente julgou a possibilidade da responsabilidade das empresas por crimes ecológicos, no entanto enfatiza que a imputação da pessoa física pode ser independente da pessoa jurídica ${ }^{7}$.

Coaduna Costa (2010) com o entendimento da Suprema Corte brasileira, ao dizer que a pessoa jurídica deve ser punida independente da pessoa física. Ou seja, não se aceita a punição por ricochete ou paralela. As culpabilidades são diferentes, enquanto a primeira tem como fundamento o risco integral, a segunda possui o finalismo do dolo ou a culpa, e, portanto, não podem se confundir.

Outro novo paradigma encontra respaldo na teoria da imputação objetiva, que consiste em defender que determinadas atividades é um risco permanente e a ocorrência desta torna-se passível de penalidade. Ou melhor, o agente criminoso responde pelo resultado independentemente de sua conduta dolosa ou culposa, mas, imputa-se por sua conduta ser geradora de um risco jurídico proibido e consequentemente a criação de um resultado jurídico.

Jesus (2000, p.33-34) explica de maneira pertinente os aspectos da teoria da imputação objetiva:

\footnotetext{
${ }^{6}$ Ver decisão: PROCESSO RESP 564960 / SC RECURSO ESPECIAL. Relator; Min. GILSON DIPP. Data do julgamento: 02/06/2005.

${ }^{7}$ Ver decisão: RE 548181 / PR - RECURSO EXTRAORDINÁRIO. Relatora: Min. ROSA WEBER. Data do julgamento: 06/08/2013.
} 


\begin{abstract}
Imputação objetiva significa atribuir a alguém a realização de uma conduta criadora de um relevante risco juridicamente proibido e a produção de um resultado jurídico. Trata-se de um dos mais antigos problemas do Direito Penal, qual seja, a determinação de quando a lesão de um interesse jurídico pode ser considerada "obra" de uma pessoa. Como o Direito Penal é teleológico, tendo em vista que está construído em relação a fins, a teoria da imputação objetiva pretende dar-lhes fundamentos, ligando a finalidade do agente ao resultado, segundo a descrição típica. É uma teoria autônoma, independente da doutrina da casualidade objetiva material. Não se encontra nos campos dos fatos, mas dos valores que o Direito Penal pretende proteger. (destaque no original)
\end{abstract}

Esta perspectiva se amolda perfeitamente a criminalidade empresarial, pois a culpabilidade neste caso não será fundada em preceitos subjetivos (dolo ou culpa), mas sim objetivamente, com base nos riscos juridicamente proibidos. "A responsabilidade do ente decorre da conduta de seus diretores e administradores, que são solidariamente responsáveis pelo evento delituoso. A responsabilidade da entidade é meramente objetiva, e nem poderia ser de outra maneira.” (PIERANGELI, 1999, p.194)

Destaca-se também a figura do biocentrismo, cuja definição reside no fato de que a tutela ambiental não pode ter o ser humano como centro do bem jurídico, mas a vida como o todo único e central. "Que el hombre debe relacionarse con la naturaleza en un marco de respeto y amor, donde e definitiva habrá de reconocerse que no sólo el hombre puede ser sujeto de derecho.”(ARCOCHA; ALENDE RUBINO, 2007, p.104-105 - destaque nosso)

Justifica-se a teoria biocêntrica quando se verifica a imensa diversidade de seres vivos conectados dentro do ecossistema, e caso ocorra um dano a uma única vida as consequências serão sentidas por todos indistintamente. E tratar o ser humano como o único sujeito de direitos no plano ecológico é desmerecer as outras vidas envolvidas no ciclo de sobrevivência.

Não se revela aqui em colocar o meio ambiente no centro da tutela jurídica (ecocentrismo), mas sim de encontrar um ponto intermediário e razoável entre o ser humano e a natureza. Esclare pertinentemente Sirvinskas (2010, p.30) sobre as diferenças destas concepções:

\footnotetext{
Antropocentrismo, ecocentrismo e biocentrismo são concepções genéricas atribuídas pelos cientistas em face da posição do homem no meio ambiente. $\mathrm{O}$ antropocentrismo coloca o homem no centro das preocupações ambientais, ou seja, no centro do universo. O ecocentrismo, ao revés, posiciona o meio ambiente no centro do universo. O biocentrismo, por sua vez, procura conciliar as duas posições extremas, colocando o meio ambiente e o homem no centro do universo. É importante ressaltar que não só o homem é destinatário da proteção ambiental, mas todas as formas de vida (art. $3^{\circ}, \mathrm{I}$, da Lei 6.938/81).
} 
Não obstante, de acordo com o entendimento de Fiorillo (2002, p.15-16), o alcance normativo do biocentrismo é possível, apesar da norma constitucional brasileira legitimar um meio ambiente claramente antropocêntrico:

\footnotetext{
De acordo com esta visão, temos que o direito ao meio ambiente é voltado para a satisfação das necessidades humanas. Todavia, aludido fato, de forma alguma, impede que ele proteja a vida em todas as suas formas, conforme determina o art. $3^{\circ}$ da Política Nacional do Meio Ambiente (Lei n.6938/81), cujo conceito de meio ambiente foi, a nosso ver, inteiramente recepcionado.

Se a Política Nacional do Meio Ambiente protege a vida em todas s suas formas, e não é só o homem que possui vida, então todos que a possuem são tutelados e protegidos pelo Direito Ambiental, sendo certo que um bem, ainda que não seja vivo, pode ser ambiental, na medida que possa ser essencial à sadia qualidade de vida de outrem, em face do que determina o art. 225 da Constituição Federal (bem material ou mesmo bem imaterial).

Dessa forma, a vida que não seja humana só poderá ser tutelada pelo direito ambiental na medida em que sua existência implique garantia da sadia qualidade de vida do homem, uma vez que numa sociedade organizada este é destinatário de toda e qualquer norma. (destaque no original)
}

Logo, enquanto a premissa antropocêntrica estiver sendo utilizada o desenvolvimento econômico e a busca do lucro sempre preponderá sobre os bens ecológicos, já que o pretexto da circulação de riquezas é algo legitimador diante da degradação dos recursos naturais.

Outra concepção muito importante é a criação de tribunais especializados na matéria ambiental, cujos processos tenham prioridades de julgamento. $\mathrm{O}$ surgimento de órgãos bem delineados e material humano devidamente treinado traria uma maior segurança jurídica na solução das causas ecológicas.

É comum no cotidiano forense os juízes, promotores de justiça, advogados e demais operadores jurídicos não possuírem conhecimento suficiente sobre a lide ambiental, isso acarreta margem para inúmeros erros de julgamento e morosidade processual. "La aparición de un Tribunal jurisdiccional es de suma importancia para la seguridad jurídica y la armonía legislativa [...].” (SOARES, 2013, p.144)

Pelo exposto, uma justiça ambiental especializada irá indubitavelmente produzir conhecimentos mais profundos sobre a matéria, e também dará ensejo a decisões mais céleres e com melhor qualidade. Vale ainda ressaltar, que mesmo diante de instituições judicantes de caráter especial não se pode deixar de existir uma interação com outros ramos de conhecimento, já que o juiz, por exemplo, no momento de decidir uma lide que envolva questões ambientais irá depender muitas vezes de pareceres técnicos de profissionais de outras áreas científicas. 
Não se pode olvidar da utilização da interdisciplinaridade no combate à criminalidade ambiental. A Ciências Jurídicas a muito tempo vem sendo uma ciência que busca suas próprias estruturas dogmáticas e que não consultar outras áreas de conhecimento por entender que o Direito por si só tem um condão suficiente de resolver todos os problemas da sociedade através de suas concepções. Pensar assim é cair em erro, pois é inconcebível diante de uma sociedade tão diversificada e em constante mutação adotar uma prática generalista.

Segundo Zaffaroni (2012) a interdisciplinaridade é um mecanismo de utilização obrigatória por causa de seu caráter enriquecedor, sob pena da Ciência Criminal não ser mais reconhecida como uma ciência. Sem os saberes de outras ciências o Direito perderá o seu sentido no combate aos delitos massivos, pois não terá argumentos dogmáticos suficientes frente a esta nova criminalidade.

Nesta linha de entendimento analisam a importância Barbosa, Soares et al (2015, p.280) do uso da interdisciplinaridade no Direito Penal e os preceitos defendidos por Eugenio Zaffaroni:

\begin{abstract}
Segundo o professor argentino a sociedade e o Direito não utilizam mais em sua essência os conhecimentos e experiências das outras ciências, não se procura utilizar mecanismos críticos aprofundados para a resolução de seus problemas cotidianos. $\mathrm{O}$ Direito, mais especificamente o Direito Penal, é utilizado ainda hoje como uma prática generalista, sem suporte teórico consistente, algo que não pode ocorrer diante dos novos acontecimentos sociais, que exigem dos estudiosos um sincretismo de conhecimentos empíricos e de teorias das mais diversas áreas científicas.
\end{abstract}

E por último, a perspectiva da vitimização massiva, significa que a vítima até então poderia ser apenas o ser humano, no entanto, a própria sociedade sentiu que além dos valores humanos existiam outros que deveriam ser preservados, como os recursos naturais, caso contrário a própria espécie humana chegaria a sua extinção.

Imenso número de valores são atingidos pela grande criminalidade ecológica, axiomas indispensáveis que estão interligados e qualquer lesão a um destes bens causa um efeito em cadeia imensurável por gerações.

Para Barbosa, Soares et al (2015, p.283), as vítimas ecológicas possuem características peculiares no processo de vitimização em massa:

O processo vitimizante ambiental é algo muito complexo, pois abrangem grupos sociais, ecossistema, países e instituições, sendo preciso apenas, que estas vítimas passem por situações de violência, degradação e limitação. A delinquência moderna não possui apenas a característica microssocial, como também, a macrossocial, é dizer, os delitos foram analisados por muito tempo por uma perspectiva muito 
individual e local, nunca se imaginou que os delitos poderiam abarcar um grande número de pessoas, de bens ou mesmo transpor as fronteiras.

Isto posto, o terrorismo ambiental geralmente é cometido por empresas altamente organizadas e cujas atividades oferecem riscos enormes ao meio ambiente. Por outro lado, os delitos ecológicos crescem diariamente e o Poder Público não possui mais força suficiente frente aos grandes grupos econômicos, é por isso, que se torna tão importante o fortalecimento do jus puniend Estatal por meio dos novos paradigmas criminológicos expostos anteriormente. 


\section{4- CONSIDERAÇÕES FINAIS}

Abordou-se que as atuações criminosas das empresas em suas atividades econômicas altamente organizadas geram o terrorismo ecológico, cujos efeitos danosos aterrorizam a sociedade como um todo. As vidas envolvidas sofrem perdas intergeracionais, ou seja, uma incalculável dívida ecológica que perdura ao longo de vários anos.

$\mathrm{Na}$ pesquisa acadêmica constatou-se, ainda que, paradigmas criminológicos inovadores como; a responsabilidade penal das pessoas jurídicas, a teoria da imputação objetiva (teoria do risco), a teoria biocêntrica, a implantação da justiça especializada, o uso da interdisciplinaridade e o surgimento da vitimização massiva, necessitam ser melhores observados pelas legislações criminais no que se refere à tutela do meio ambiente e no combate a macrocriminalidade.

Detectou-se também, que a atuação do Direito Penal na seara ambiental não interferirá de modo algum no desenvolvimento econômico da sociedade, todavia, ao revés, pois proporcionará um aporte imprescindível na preservação ambiental e desenvolvimento sustentável na medida que coíbe o resultado criminoso.

Verificou-se, por fim, que a busca de conhecimentos em outras ciências afins, como também, o estudo e a quebra de paradigmas criminológicos em relação ao terrorismo ambiental não se traduz em um mero expansionismo das leis penais movido por uma política criminal midiática e imediatista, mas sim uma maneira de coibir eficazmente as novas formas de criminalidade ecológica massiva. 


\section{5- REFERÊNCIAS}

ARCOCHA, Carlos Enrique; ALLENDE RUBINO, Horacio L. Tratado de Derecho Ambiental. Rosario: Nova Tesis Editorial Jurídica, 2007.

BACIGALUPO, Silvina. Responsabilidad Penal de las Personas Jurídicas. Buenos Aires: Editorial Hammurabi SRL, 2001.

BARBOSA, Erivaldo Moreira; MEDEIROS, Orione Dantas de; RABBANI, Roberto M. Rahnemay; SOARES, Jardel de Freitas. Direito Constitucional e Direito Ambiental: Diálogos possíveis. São Paulo: Max Limonad, 2015.

BRASIL. LEI DE PROTEÇÃO AMBIENTAL DA REPÚBLICA FEDERATIVA DO BRASIL DE 12 DE FEVEREIRO DE 1998- número 9.605/98. Disponível em <http://www.planalto.gov.br/ccivil_03/Leis/L9605.htm>. Acesso em: 03 de ago. 2016.

. LEI QUE REGULAMENTE O TERRORISMO DA REPÚBLICA FEDERATIVA DO BRASIL DE 16 DE MARÇO DE 2016- número 13260/16. Disponível em <http://www.planalto.gov.br/ccivil_03/_Ato2015-2018/2016/Lei/L13260.htm> Acesso em: 03 de ago. 2016.

CÓDIGO PENAL - CÓDIGO DE PROCESSO PENAL - CONSTITUIÇÃO FEDERAL DO BRASIL. São Paulo: Saraiva, 2016.

COSTA, Helena Regina Lobo da. Proteção Penal Ambiental: Viabilidade - Efetividade Tutela por outros ramos do direito. São Paulo: Saraiva, 2010.

CUNHA, Ciro Leal M. da. Terrorismo Internacional e a Política Externa Brasileira Após o 11 de Setembro. Brasília: Fundação Alexandre de Gusmão, 2009.

FATTORELLI, Maria Lucia. Terrorismo Ambiental e a Dívida Ecológica. 2015. Disponível em< http://www.cadtm.org/Terrorismo-ambiental-e-divida >. Acesso em: 16 de ago. 2016.

FERRAJOLI, Luigi. Direito e Razão: Teoria do garantismo penal. São Paulo: Editora RT, 2013.

FIORILlO, Celso Antonio Pacheco. Curso de Direito Ambiental Brasileiro. São Paulo: Saraiva, 2002.

GOMES - JARA DÍEZ, Carlos. Fundamentos Modernos de La Responsabilidad Penal de las Personas Jurídicas: Bases teóricas, regulación internacional y nueva legislacíon española. Buenos Aires/ Montevideo: Editorial B de F Ltda, 2010.

JAKOBS, Günther. ¿Punibilidad de las personas jurídicas? In: CAVERO, Percy García (coordenador). La responsabilidad penal de las personas jurídicas, órganos $\mathbf{y}$ representantes. Mendoza: Ediciones jurídicas cuyo, 2004. 
; MELIÁ, Manuel Cancio. Direito Penal do Inimigo: Noções e críticas. Porto Alegre: Livraria do Advogado, 2007.

JESUS, Damásio E. de. Imputação Objetiva. São Paulo: Saraiva, 2000.

LORENZETTI, Ricardo Luis. Teoria Geral do Direito Ambiental. São Paulo: Editora RT, 2010.

MARCÃO, Renato. Crimes Ambientais: Anotações e interpretação jurisprudencial da parte criminal da lei n. 9605, de 12-2-1998. São Paulo: Saraiva, 2013.

MILARÉ, Édis; COSTA JÚNIOR, Paulo José da; COSTA, Fernando José da. Direito Penal Ambiental. São Paulo: Editora RT, 2013.

PIERANGELI, José Henrique. Escritos Jurídico-Penais. São Paulo: Editora RT, 1999.

PRADO, Luiz Regis. Direito Penal do Ambiente. São Paulo: Editora RT, 2005.

ROCHA, Fernando A. N. Galvão da. Responsabilidade Penal da Pessoa Jurídica. Belo Horizonte: Del Rey, 2003.

ROXIN, Claus. Tem futuro o direito penal? In: Estudos de Direito Penal. Rio de Janeiro: Renovar, 2008.

SIRVINSKAS, Luís Paulo. Tutela Constitucional do Meio Ambiente. São Paulo: Saraiva, 2010.

SOARES, Jardel de Freitas. La Criminalidad Ambiental de las Empresas en el Mercosur. Cajazeiras: Real, 2013.

ZAFFARONI, Eugenio Raúl. Crímenes de Masa. Buenos Aires: Ediciones Madres de Plaza de Mayo, 2012.

Parecer a Nilo Batista sobre a responsabilidade penal da pessoa jurídica. In: PRADO, Luiz Regis. DOTTI, René Ariel (coordenadores). Responsabilidade Penal da Pessoa Jurídica - em defesa do princípio da imputação penal subjetiva. São Paulo: RT, 2010. 